\title{
Uranium and Thorium Concentrations in an Estuary Affected by Phosphate Fertilizer Processing: Experimental Results and a Modelling Study
}

\author{
R. Periáñez \& A. Martínez-Aguirre \\ Dpto Física Aplicada, E.U. Ingeniería Técnica Agrícola, Universidad de Sevilla, Ctra \\ Utrera km 1, 41014 Sevilla, Spain
}

(Received 16 February 1996; accepted 25 June 1996)

\begin{abstract}
The Odiel river, in southwest Spain, forms an estuarine system which is affected by waste disposal from a fertilizer complex. Uranium and thorium concentrations in waters and suspended matter, activity ratios and distribution coefficients, $\mathrm{k}_{d}$, have been measured along the river during two different tidal states. The results have shown that a radioactive impact is being delivered to the river, as well as a significant variability depending on the sampling point and the tidal state. Thus, a quantitative study of the distribution of radionuclides can be carried out best by means of a mathematical model. The model includes the partition of radiotracers between four phases (water, suspended matter and two sediment fractions) and has been designed for non-equilibrium conditions. Thus, radiotracer transfers are described in terms of kinetic transfer coefficients instead of $\mathbf{k}_{d} s$. The model simultaneously solves the hydrodynamic equations, the suspended matter equation (including depostion and resuspension processes) and the equations which describe the time evolution of radionuclide concentrations in each one of the four phases. The model has yielded good results in predicting $U$ and Th concentrations in water and suspended matter, distribution coefficients and Th/U mass ratios. (O) 1997 Published by Elsevier Science Limited. All rights reserved
\end{abstract}

\section{INTRODUCTION}

The Odiel river is located in the southwest of Spain. At its lowest reaches, it forms a tidal estuarine system which discharges into the Atlantic Ocean. 
The estuary is close to a large industrial area in which a phosphate fertilizer processing complex operates. This complex processes around 1.6 MT of phosphate rock per year from Morocco, Senegal and Togo. Part of the waste is released directly into the Odiel river.

It is well known (Van der Heijde et al., 1988; Laiche \& Scott, 1991) that such wastes contain significant amounts of natural radionuclides: $U, T h$, $\mathrm{Ra}$ and their daughters. The presence of ${ }^{226} \mathrm{Ra}$ and ${ }^{224} \mathrm{Ra}$ in water and suspended matter samples collected from the Odiel river has already been investigated (Periáñez \& Garcia-León, 1993; Periáñez et al., 1994a). These studies have revealed that a radioactive impact is being delivered to the river since, for instance, levels up to $670 \mathrm{mBq}^{-1}$ of ${ }^{226} \mathrm{Ra}$ have been measured in a water sample collected close to the fertilizer complex.

Although there are data on the U- and Th-isotope content in the Odiel river water and suspended matter (Martínez-Aguirre et al., 1994a), a more detailed study is reported in this paper. The objective of this work is to understand the $U$ and $T h$ dispersion mechanisms in dynamic aquatic systems, including the distribution between the solid and liquid phases as well as the effect of tidal oscillations. Thus, water samples were collected along the Odiel river at two different tidal states (high and low water) and the U- and Th-isotope contents in water and suspended matter were measured. The distribution coefficients $k_{\mathrm{d}}$ were also calculated. A qualitative description of the results is not straightforward as there is significant variability in activity concentrations and $k_{\mathrm{d}}$, depending upon the sampling point and the tidal state. This is a logical result since we are dealing with an open system in which some different effects are taking place at the same time: non-constant input from the source, adsorption of radionuclides on to suspended matter and bottom sedimens, desorption, and water and suspended matter movements due to tides. Thus, a quantitative understanding of the $\mathrm{U}$ and $\mathrm{Th}$ dispersion can be achieved best by means of mathematical models.

A two-dimensional model, that includes the transfer processes between four phases (water, suspended matter and two grain size fractions of bottom sediments), has been applied to the Odiel river. The model simultaneously solves the hydrodynamic equations, the suspended matter dynamic equation (including the resuspension and deposition processes) and the equations that describe the time evolution of radionuclide concentrations into each of the four phases. Although the model has been previously applied to study the dispersion of ${ }^{226} \mathrm{Ra}$ in the Odiel river (Periáñez et al., 1996a), there are two main objectives in applying it to $\mathrm{U}$ and Th: to achieve a quantitative understanding of the experimental results and to provide extra validation of the model, that is, to validate the model for elements with very different geochemical behaviours, such as $\mathrm{U}$ and $\mathrm{Th}$. 
In the next section, the sampling and experimental methods are described. Next, the experimental results are discussed. The modelling work is described in Section 4.

\section{EXPERIMENTAL}

Water samples were collected in plastic bottles along the Odiel river basin (see Fig. 1) during July 1990. Two samples were collected from each sampling station: one during high water and the other during low water so as to study the influence of tidal oscillations on the results. The water was filtered as soon as possible through previously weighed Nuclepore filters $(0.4 \mu \mathrm{m}$ pore size) to separate the suspended matter. The filter was then dried and weighed to calculate the mass of recovered matter. Typical suspended matter concentrations in the Odiel river ranged from 24 to $50 \mathrm{ppm}$, depending on the sampling point and the tidal state during sampling. The filter was then covered with $\mathrm{HCl}$ and introduced into an ultrasonic bath for half an hour, during which, the suspended matter was separated from the filter and dissolved. The filter was then washed with

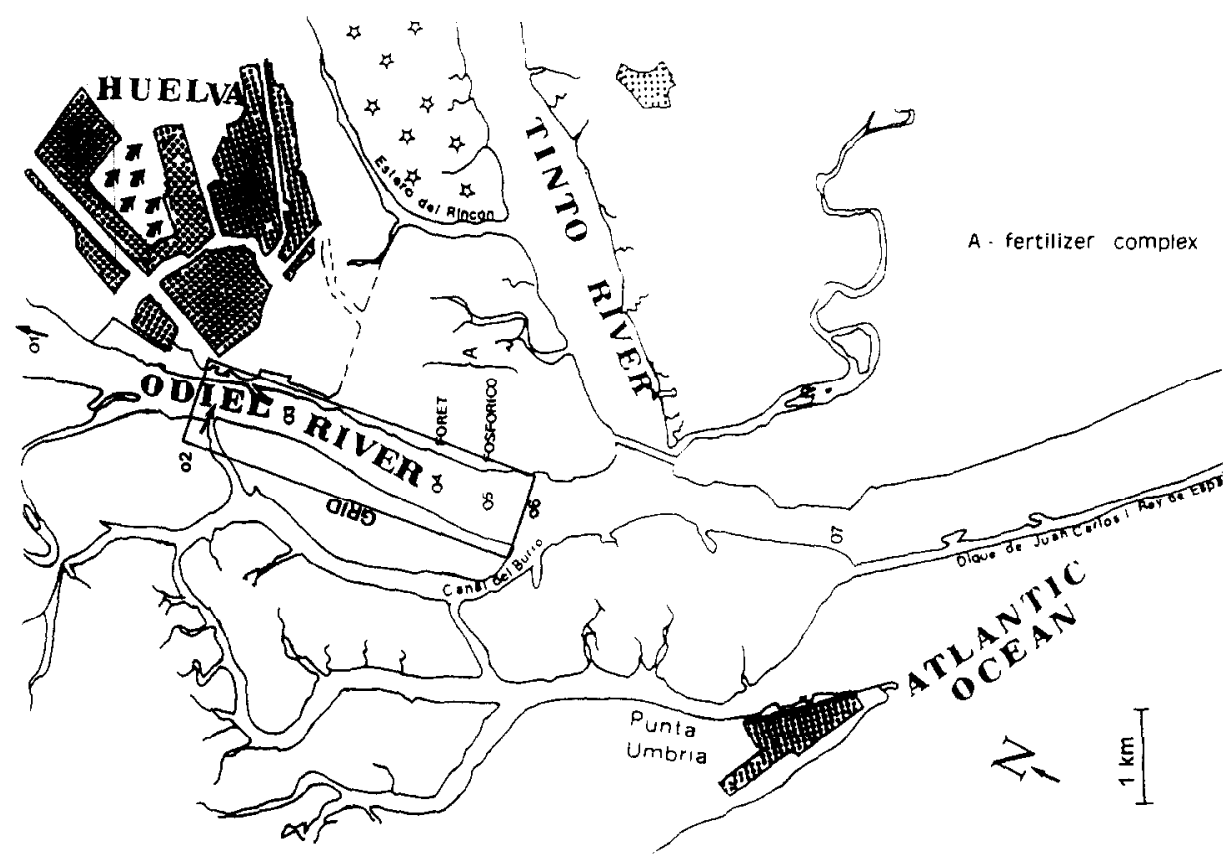

Fig. 1. Map of the Odiel river showing the sampling points. The rectangular box is the grid used in the model. 
$\mathrm{HNO}_{3}$ which was added to the $\mathrm{HCl}$ to form aqua regia. This solution was slowly heated to dissolve all remaining particles.

Uranium-232 and ${ }^{229} \mathrm{Th}$ spikes and Fe carrier were added to the filtered water and to the solution obtained after the dissolution of suspended matter particles. Precipitation of Fe with oxyhydroxides with concentrated amonium then followed.

Uranium- and Th-isotopes were extracted from the precipitates by using anion exchange resins (DOWEX $\mathrm{AG} 1 \mathrm{X} 8, \mathrm{HCl}$ form) and electroplated on to stainless steel planchets. Activities were measured with Si ion-implanted detector alpha spectrometry. Details of the radiochemical and measurement methods can be found in Martínez-Aguirre (1991).

\section{EXPERIMENTAL RESULTS}

Water samples are denoted by ' $\mathrm{O}$ ' and suspended matter samples by 'SO'. The numbers given to each sample identify the sampling stations (see Fig. 1), which are distributed along the low reaches of the river, close to the fertilizer complex. Station 1 is, however, far upstream of this area. As it is not believed to be affected by tidal oscillations, only one sample was collected there.

The results for low and high water suspended matter samples are presented in Tables 1 and 2, respectively. In the case of the low water samples, there is a high concentration peak at station $\mathrm{SO} 4$, for both $U$ and $\mathrm{Th}$, revealing the presence of a local source of activity. Up to 86 and $116 \mu \mathrm{g} \mathrm{g}^{-1}$ of $\mathrm{U}$ and $\mathrm{Th}$, respectively, have been measured in this sample, values which are much higher than those previously found for suspended matter samples collected from other rivers. Indeed, $U$ concentrations ranging from 1.8 to $2.4 \mu \mathrm{gg}^{-1}$ have been detected in the Amazon and Mississippi rivers (Moore, 1967). On the other hand, Th concentrations in these rivers range from some 8 to $10 \mu \mathrm{g} \mathrm{g}^{-1}$ (Moore, 1967). In some Japanese rivers, Th concentrations range from some 2.2 to $6.7 \mu \mathrm{g} \mathrm{g}^{-1}$ (Miyake et al., 1973). Thus, it seems clear that samples SO4 and SO5, collected close to the fertilizer complex, are affected by the waste disposal from the complex.

In the case of the high water suspended matter samples, the distribution of $\mathrm{Th}$ and $\mathrm{U}$ is different. The maximum $\mathrm{Th}$ concentration is $0.7 \mu \mathrm{gg}^{-1}$, and there is a general homogenization of concentration levels. This could be due to tidal mixing, input of non-contaminated suspended matter from the sea and a non-constant input of contaminants from the source (the fertilizer complex). On the other hand, $U$ concentrations are also lower than during low water, although there is still an important peak in sample 
TABLE 1

Concentrations of $\mathrm{U}$ and $\mathrm{Th}\left(\mu \mathrm{g} \mathrm{g}^{-1}\right)$ for the Suspended Matter Samples Collected During Low Water, and Activity Ratios

\begin{tabular}{cccccc}
\hline Sample & {$[U]$} & {$[T h]$} & $\left.{ }^{234} U\right|^{238} U$ & ${ }^{230} T h{ }^{232} T h$ & $T h / U$ \\
\hline SO1 & $1.10 \pm 0.24$ & & $1.2 \pm 0.3$ & & \\
SO2 & $1.08 \pm 0.13$ & $0.07 \pm 0.04$ & $1.27 \pm 0.14$ & $7 \pm 4$ & $0.06 \pm 0.04$ \\
SO3 & $2.03 \pm 0.24$ & $0.11 \pm 0.05$ & $1.39 \pm 0.17$ & $9 \pm 4$ & $0.05 \pm 0.03$ \\
SO4 & $86 \pm 10$ & $116 \pm 6$ & $0.98 \pm 0.05$ & $5.28 \pm 0.13$ & $1.35 \pm 0.17$ \\
SO5 & $25.3 \pm 1.3$ & $31 \pm 3$ & $1.00 \pm 0.07$ & $6.1 \pm 0.7$ & $1.22 \pm 0.13$ \\
SO6 & $13.4 \pm 1.5$ & $0.052 \pm 0.024$ & $1.07 \pm 0.17$ & $2.4 \pm 1.4$ & $(3.9 \pm 1.8) \times 10^{-3}$ \\
SO7 & $19.1 \pm 1.7$ & & $1.06 \pm 0.06$ & & \\
\hline
\end{tabular}

Errors are $1 \sigma$.

TABLE 2

Concentrations of $\mathrm{U}$ and $\mathrm{Th}\left(\mu \mathrm{gg}^{-1}\right)$ for the Suspended Matter Samples Collected During High Water, and Activity Ratios

\begin{tabular}{cccccc}
\hline Sample & {$[U]$} & {$[T h]$} & ${ }^{234} U l^{238} U{ }^{230} \mathrm{Th}^{232} \mathrm{Th}$ & $T h / U$ \\
\hline SO1 & $1.10 \pm 0.24$ & & $1.2 \pm 0.3$ & & \\
SO2 & $3.9 \pm 0.5$ & $0.12 \pm 0.07$ & $1.12 \pm 0.16$ & $13 \pm 8$ & $0.031 \pm 0.018$ \\
SO3 & $2.8 \pm 0.3$ & $0.19 \pm 0.07$ & $1.09 \pm 0.10$ & $3.2 \pm 1.4$ & $0.07 \pm 0.03$ \\
SO4 & $9.0 \pm 1.0$ & $0.27 \pm 0.13$ & $1.24 \pm 0.10$ & $17 \pm 9$ & $0.030 \pm 0.015$ \\
SO5 & $69 \pm 3$ & & $1.04 \pm 0.07$ & & \\
SO6 & $1.6 \pm 0.4$ & $0.06 \pm 0.04$ & $0.9 \pm 0.3$ & $8 \pm 5$ & $0.04 \pm 0.03$ \\
SO7 & $2.4 \pm 0.4$ & $0.7 \pm 0.2$ & $0.91 \pm 0.17$ & $5.1 \pm 1.9$ & $0.29 \pm 0.10$ \\
\hline
\end{tabular}

Errors are $1 \sigma$.

SO5, which is close to the fertilizer complex. This effect has already been observed for ${ }^{226} \mathrm{Ra}$ (Periáñez et al., 1994a).

In general, ${ }^{234} \mathrm{U} /{ }^{238} \mathrm{U}$ activity ratios are compatible with the existence of secular equilibrium in samples in which high $U$ concentrations have been detected. This is not a typical feature of rivers, but it is typical of the minerals used for fertilizer production (Martínez-Aguirre et al., 1994a). The secular equilibrium found suggests an external origin for the suspended matter particles, which must be the fertilizer complex.

The ${ }^{230} \mathrm{Th} /{ }^{232} \mathrm{Th}$ activity ratios are higher than 1 all along the river for both high and low water suspended matter samples. This reveals the high contamination by members of the ${ }^{238} U$ radioactive chain.

The existence of an external source of activity is confirmed from the Th/ $U$ mass ratios. Since $U$ is considerably more soluble than $T h$, it is often found in deficit with respect to Th in the solid surface environment. Thus, suspended matter in unperturbed rivers usually has $\mathrm{Th} / \mathrm{U}$ mass ratios 
above 1. This is not the case with the Odiel river. It can be seen, in Tables 1 and 2, that, with the exception of samples SO4 and SO5 in low water, the $\mathrm{Th} / \mathrm{U}$ mass ratios are below 1 . This confirms the existence of an external source of $U$ contaminated particles to the river. The exceptions mentioned above show ratios above 1, values which are typical of unperturbed rivers' suspended particles (although they are the most contaminated samples). These results will be discussed further, with the help of the mathematical model.

The results for the water samples are presented in Table 3. Unfortunately, only the low water samples could be measured (due to technical problems in the laboratory). Sample O1 shows an anomalously high $\mathrm{U}$ concentration with respect to the rest of the data. The very low $\mathrm{pH}$ of the water, 2.86 (Periáñez \& García-León, 1993), due to local geology conditions (Martínez-Aguirre et al., 1994b), accounts for the enhanced U concentration. The acid waters around station 1 provoke a dissolution of $\mathrm{U}$ from the solid phase (suspended matter and bottom sediments) to the liquid phase. This effect has also been observed for Ra-isotopes (Periáñez \& García-León, 1993). The $\mathrm{pH}$ of waters downstream from station $\mathrm{Ol}$ ranges from 6.3 to 7.6 ; thus, this effect does not take place (Periáñez \& García-León, 1993). High U concentrations are also observed all along the studied area with a peak around sample O4, close to the complex. Indeed, $\mathrm{U}$ concentrations in river water range from some $0.02 \mu \mathrm{gl}^{-1}$ in the Amazon river (Bertine et al., 1970) to some $3.5 \mu \mathrm{gl}^{-1}$ in the Nahe river (Mangini et al., 1979). Similar values were found in some Indian rivers (Bhat \& Krishnaswamy, 1969). Thus, it seems that an input of Ucontaminated water is taking place around the sampling station O4. This input is again probably related to the operation of the fertilizer complex.

In the case of Th, concentrations at least one order of magnitude higher

TABLE 3

Concentrations of $\mathrm{U}$ and Th in Water Samples $\left(\mu \mathrm{gl}^{-1}\right)$ Collected During Low Water, and Activity Ratios

\begin{tabular}{cccccc}
\hline Sample & {$[U]$} & {$[T h]$} & $\left.{ }^{234} U\right|^{238} U$ & ${ }^{230} T h{ }^{232} T h$ & $T h / U$ \\
\hline O1 & $7.5 \pm 0.3$ & & $1.89 \pm 0.03$ & & \\
O2 & $2.85 \pm 0.16$ & $0.102 \pm 0.018$ & $1.09 \pm 0.05$ & $7.9 \pm 1.4$ & $0.014 \pm 0.003$ \\
O3 & $3.09 \pm \mathbf{0 . 1 8}$ & $\mathbf{0 . 1 4 7} \pm 0.020$ & $1.02 \pm 0.04$ & $7.5 \pm 1.0$ & $0.048 \pm 0.007$ \\
O4 & $6.9 \pm \mathbf{0 . 4}$ & $8.4 \pm 1.0$ & $1.00 \pm 0.05$ & $5.4 \pm 0.02$ & $1.22 \pm 0.16$ \\
O5 & $5.3 \pm 0.3$ & $\mathbf{0 . 5 8} \pm 0.19$ & $1.06 \pm 0.09$ & $11 \pm 4$ & $0.11 \pm 0.04$ \\
O6 & $4.5 \pm \mathbf{0 . 3}$ & $\mathbf{0 . 2 9} \pm 0.05$ & $1.09 \pm 0.11$ & $5.8 \pm 1.1$ & $0.064 \pm 0.012$ \\
O7 & $4.98 \pm \mathbf{0 . 2 4}$ & $\mathbf{0 . 1 4} \pm 0.02$ & $1.08 \pm 0.04$ & $7.4 \pm 1.2$ & $0.028 \pm 0.004$ \\
\hline
\end{tabular}

Errors are $1 \sigma$. 
than in other non-perturbed world rivers (Moore, 1967; Miyake et al., 1973) have been detected. A high concentration peak $\left(8.4 \mu \mathrm{gl}^{-1}\right)$ has been found in sample $\mathrm{O} 4$, probably related to the operation of the complex.

The ${ }^{234} \mathrm{U} /{ }^{238} \mathrm{U}$ activity ratios are, in general, compatible with the existence of secular equilibrium. This is not the typical disequilibrium observed in river waters (Scott, 1982), but is typical of the minerals used for fertilizer production. The high ratio observed in sample $\mathrm{O} 1$ must be due to the higher trend of ${ }^{234} \mathrm{U}$ to be dissolved. The ${ }^{230} \mathrm{Th} /{ }^{232} \mathrm{Th}$ activity ratio is above unity all along the river, indicating greater contamination by radionuclides of the ${ }^{238} \mathrm{U}$ radioactive chain. Finally, the $\mathrm{Th} / \mathrm{U}$ mass ratio is, with the exception of sample $\mathrm{O} 4$, below unity. This is consistent with the trend of Th being associated with the solid phases in rivers. The exception must be, as in the case of suspended matter, related to the contaminants. This will be discussed later, with the help of modelling.

$k_{\mathrm{d}}$ distribution coefficients between suspended matter and water for ${ }^{238} \mathrm{U},{ }^{232} \mathrm{Th}$ and ${ }^{230} \mathrm{Th}$ are presented in Table 4 . In the case of ${ }^{238} \mathrm{U}$, our results are in agreement with the values found in literature. Indeed, $k_{\mathrm{d}}$ for $\mathrm{U}$ in coastal water can range from 0.2 to $51 \mathrm{~g}^{-1}$, the mean value being $1 \mathrm{~g}^{-1}$ (IAEA, 1985). The $k_{\mathrm{d}} \mathrm{s}$ are very similar for both Th-isotopes, indicating that they are distributed between water and suspended matter in the same way. However, values below the range of variation which can be found in the literature (IAEA, 1985) have been obtained. Nevertheless, a clear conclusion of these results is the large $k_{\mathrm{d}}$ variation between different sampling points (up to two orders of magnitude). This variation comes from the $k_{\mathrm{d}}$ definition itself: it assumes an equilibrium situation for the exchanges between the solid and liquid phases. This situation is not always achieved when an in-situ measurement of $k_{\mathrm{d}}$ is performed, especially in sites where the input into the system is changing with time (man-made pollution). Thus, when a $k_{\mathrm{d}}$ measurement is carried out, an extensive

\section{TABLE 4}

Distribution Coefficients $\left(\mathrm{lg}^{-1}\right)$ for the Low-water Samples

\begin{tabular}{cccc}
\hline Sample & ${ }^{238} U$ & ${ }^{232} \mathrm{Th}$ & ${ }^{230} \mathrm{Th}$ \\
\hline O1 & $0.15 \pm 0.3$ & & \\
O2 & $0.38 \pm 0.05$ & $0.7 \pm 0.4$ & $0.59 \pm 0.17$ \\
O3 & $0.91 \pm 0.12$ & $0.7 \pm 0.3$ & $0.91 \pm 0.17$ \\
O4 & $12.5 \pm 1.6$ & $13.8 \pm 1.8$ & $13.3 \pm 1.6$ \\
O5 & $4.8 \pm 0.4$ & $53 \pm 18$ & $30 \pm 4$ \\
O6 & $3.0 \pm 0.4$ & $0.2 \pm 0.1$ & $0.07 \pm 0.02$ \\
O7 & $3.8 \pm 0.4$ & & \\
\hline
\end{tabular}

Errors are $1 \sigma$. 
description of the sampling conditions ( $\mathrm{pH}$, temperature and salinity) should be made in order to interpret the result. In open dynamic systems, such as in an estuary, equilibrium conditions will probably never be reached. Thus, mathematical models designed for non-equlibrium conditions are important tools to study the dispersion of radionuclides in dynamic aquatic systems.

\section{THE MODELLING STUDY}

\subsection{Model description}

The first models which were developed to study the dispersion of nonconservative radionuclides in aquatic systems were averaged box models in which the exchanges of radionuclides between the liquid and solid phases were described in terms of $k_{\mathrm{d}}$, assuming complete equilibrium in the system (Howorth and Eggleton, 1988; Abril \& Garcia-León, 1993). However, in open systems where the input is changing with time (as in the case of man-made pollution) and when studying the dispersion of radionuclides in small coastal regions (such as estuaries), the equilibrium approach will not hold. This is due to the fact that, because of the high spatial and temporal resolutions that are imposed by the numerical scheme, the equilibrium will not be reached in each time step (Periáñez et $a l ., 1996 b)$. In these cases, a kinetic approach is more appropriate. Thus, the equilibrium will be the dynamic balance between two opposite chemical reactions (Nyffeler et al., 1984). The model developed to study the dspersion of radionuclides in the Odiel river estuary (which, of course, could be applied to any other site) makes use of this kinetic approach. The model is presented in detail in Periáñez et al. (1996b); thus, only a brief description of the processes that are included will be given here.

The system under study is divided into a number of grid cells or 'compartments'. Four phases or subcompartments are present in each grid cell, which are water, suspended matter and two sediment grain size fractions. In Fig. 2, a grid cell is shown. Radionuclides can be dissolved or associated with suspended matter. As tides produce a continuous movement of water, radionuclides in both phases will be transported from one grid cell to another by advective and diffusive processes. Only particles with a diameter $\phi<62.5 \mu \mathrm{m}$ are considered to be present in the water column as suspended matter (Gurbutt et al., 1987): larger particles will rapidly sink to the bottom. In sediments, we will consider two grain size fractions: particles with diameter $\phi<62.5 \mu \mathrm{m}$ (small grain size fraction) and particles with $\phi>62.5 \mu \mathrm{m}$ 


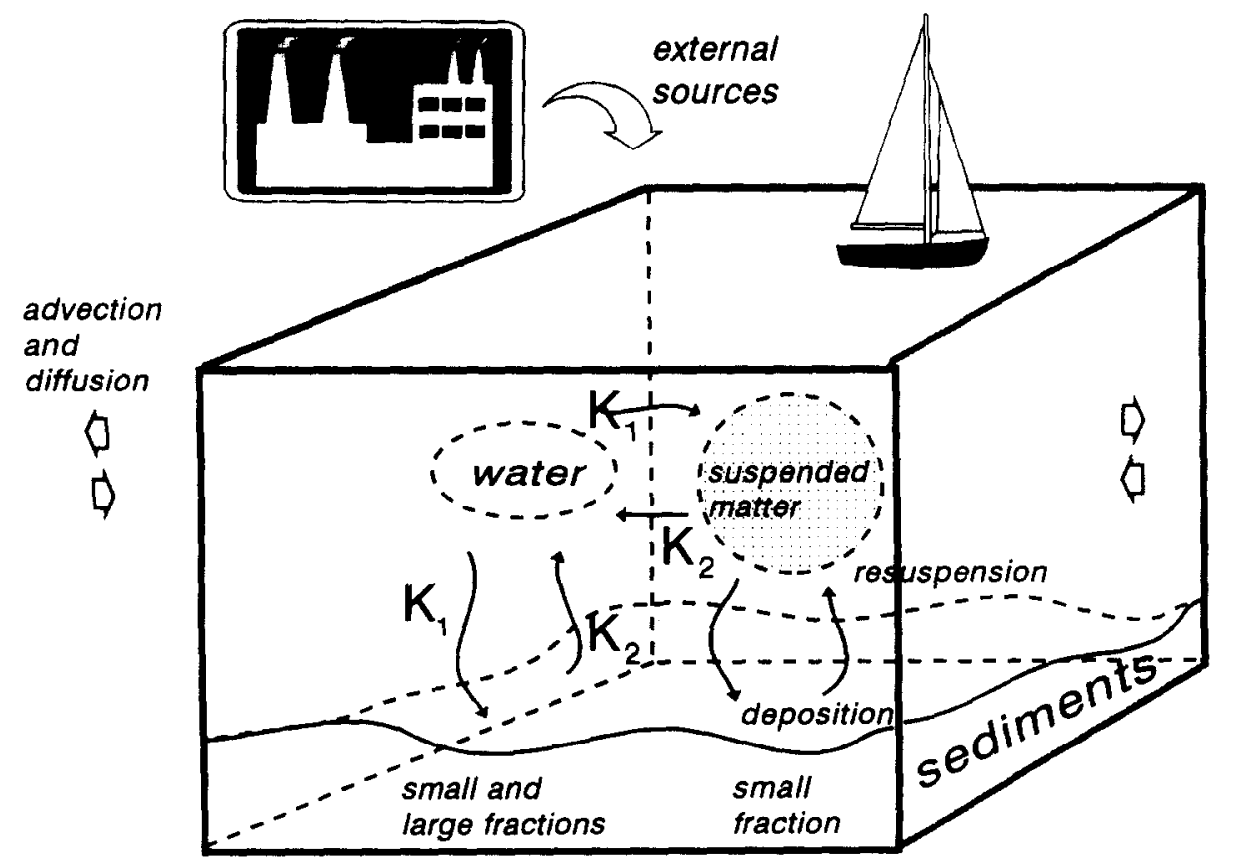

Fig. 2. Grid cell in which the radionuclide transfer processes between the four phases are represented.

(large grain size fraction). Only the small grain size fraction can be resuspended in the water column and incorporated into suspended matter. On the other hand, when suspended matter is desposited on the estuary bed, it will be incorporated into the small grain size fraction of the sediments. Thus, the deposition and resuspension processes produce an exchange of radionuclides between the suspended matter and the small grain size fraction of the sediment. The water is in contact with the other three phases; thus, adsorption and desorption reactions take place. These reactions are described in terms of kinetic transfer coefficients. Finally, external sources of radionuclides (in dissolved and suspended phases) may exist in each grid cell.

We will consider that the adsorption process (transfer from water to the solid phases) is governed by a coefficient $k_{1}$ and the inverse process (desorption towards the liquid phase) by a coefficient $k_{2}$.

The adsorption process is a surface phenomenon and will depend on the surface of particles per water volume unit into the grid cell. This quantity will be denoted the exchange surface. If we now consider only suspended matter as the solid phase (ncglecting sediments), we have:

$$
k_{1}=\chi_{1} S_{\mathrm{s}},
$$


where $S_{\mathrm{s}}$ is the exchange surface for suspended matter. $\chi_{1}$ has the dimension of velocity and will be described as the exchange velocity, which depends on the selected radionuclide and the water conditions (salinity, temperature and $\mathrm{pH}$ ). As a first approach, assuming a step function for the grain size distribution of particles, it can be easily shown (Periáñez et al., 1996b) that:

$$
S_{\mathrm{s}}=\frac{3 m}{\rho R}
$$

where $m$ is the suspended matter concentration in water, $\rho$ the suspended matter particles density and $R$ their mean radius.

We must now consider that radionuclides will also be incorporated into bottom sediments by direct adsorption. The water-sediment interface can be considered as a high $m$ environment ( $\mathrm{Li}$ et al., 1984). Thus, the total exchange surface will be $S=S_{\mathrm{s}}+S_{\mathrm{sf}}+S_{\mathrm{lf}}$, where $S_{\mathrm{sf}}$ and $S_{\mathrm{If}}$ are the exchange surfaces for the small and the large grain size fractions of sediments, respectively. It can be shown (Periáñez et al., 1996b) that the global $k_{1}$ is:

$$
k_{1}=\chi_{1}\left(\frac{3 m}{\rho R}+\frac{3 L f \psi}{R H}+\frac{3 L(1-f) \psi^{\prime}}{R_{1} H}\right),
$$

where $L$ is the average mixing depth (the distance until which the dissolved phase penetrates the sediment), $f$ is the dry weight fraction of small particles in the sediment, $R_{l}$ is the mean radius of the large grain size fraction particles, $H$ is the height of the water column and $\psi$ and $\psi^{\prime}$ are geometrical accessibility factors (one for each sediment fraction) which take into account that not all the mass of the sediment is in contact with water.

Four equations are then obtained, which give the time evolution of specific activity into each phase, including all the above-mentioned processes. These equations can be seen in detail in Periáñez et al. (1996b) and a summary is presented in the Appendix. The equations have to be solved at each time step. Thus, the water column height, the water velocity and the suspended matter concentration must be known for each time step and for each grid cell since $k_{1}$ and the advective-diffusive transport have to be calculated.

The water circulation is obtained from the shallow-water hydrodynamic equations, whose solutions give the instantaneous water displacement from the mean level due to tides and the water velocity for each grid cell. The equations include the convective terms, Coriolis term, bed friction, response to wind stress and response to changes in atmospheric pressure. 
They can be seen in detail in, for instance, Pugh (1987) and Prandle (1984). A spatial and temporal discretization of the equations is carried out and a finite difference scheme is adopted to solve them. This numerical scheme can be seen in detail in Flather and Heaps (1975) and Flather (1994). Resolutions of the model (grid cells size and time step) are selected so as to satisfy a stability condition (Prandle, 1974) and to minimize numerical dispersion (Periáñez et al., 1994b).

As stated above, not only the instanteneous water state, but also the suspended matter concentration, $m$, into each grid cell for each time step must be known. An advective-diffusive dispersion equation governs the horizontal movement of suspended matter. The vertical movement is governed by deposition and resuspension processes (Periáñez et al., 1996c). These have been formulated in terms of critical deposition and resuspension velocities in such a way that there is deposition only if the water velocity is smaller than the critical deposition velocity. For larger values of the water velocity, deposition is hindered by the water turbulence. On the other hand, there is resuspension only if the water velocity is larger than the critical resuspension velocity; otherwise, there will not be enough energy to lift particles from the sediments. To solve the suspended matter equation, the advective-diffusive dispersion equation must be written in terms of finite differences. This numerical scheme can be seen in Periáñez et al. (1994b).

The resolution of the hydrodynamic equations to obtain the water circulation in the Odiel river and the resolution of the suspended matter equation to study the sedimentology of the same river can be seen, respectively, in Periáñez et al. $(1994 b, c)$. As an example, Fig. 3 illustrates the grid used to solve the equations, a map of water elevations and currents during the flood tide and a map of the averaged sedimentation rates. The model resolutions are: $\Delta x=\Delta y=100 \mathrm{~m}, \Delta t=6 \mathrm{~s}$.

Thus, for each time step and for each grid cell, the hydrodynamic equations must be solved to obtain the water elevations and velocities. Next, the suspended matter equation is solved to obtain the suspended matter concentration and the resuspension and deposition terms. Finally, the four equations that govern the time evolution of specific activity in each phase arc solved.

\subsection{Model results}

The parameters involved in the model used to simulate the dispersion of $U$ and Th are those that were used to simulate the ${ }^{226} \mathrm{Ra}$ dispersion, with the exception of the kinetic transfer coefficients. Of course, the mean radius of suspended matter, for instance, does not depend upon whether we are 

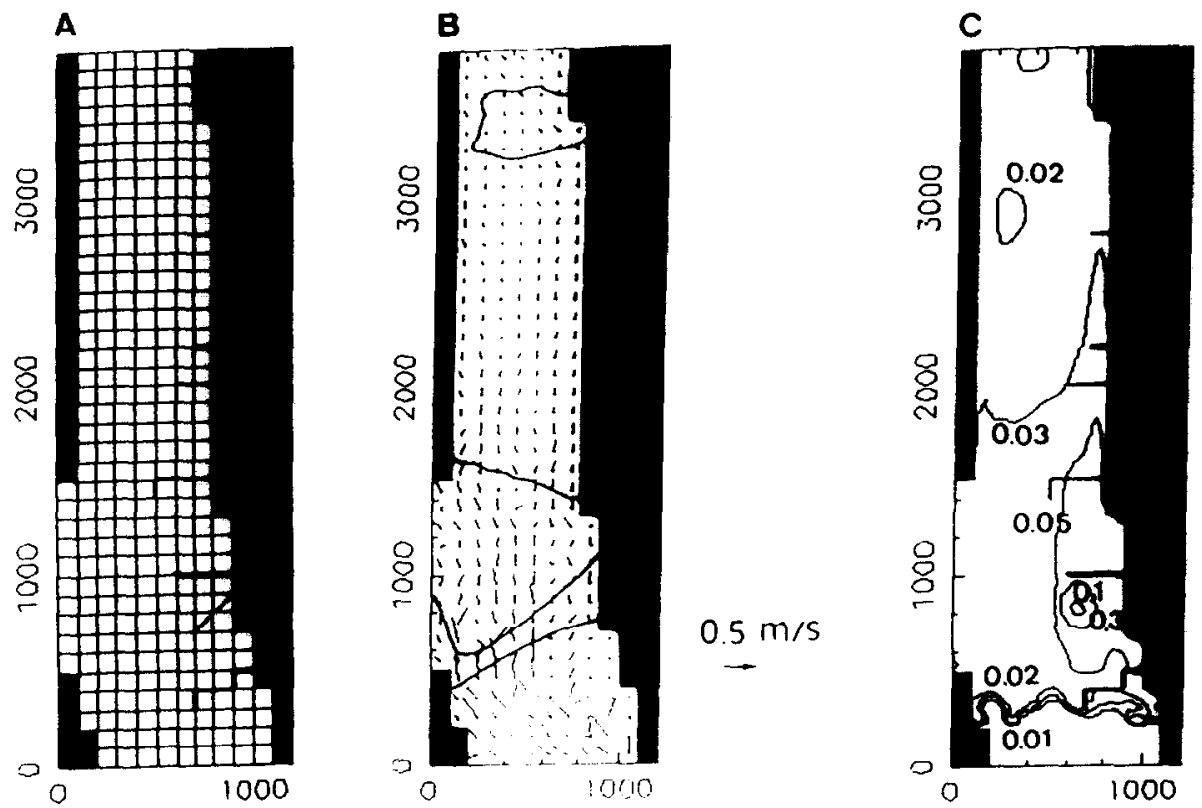

Fig. 3. (A) Grid used in the model. The dimensions of the compartments are $\Delta x=\Delta y=100 \mathrm{~m}$. (B) Water elevation and velocity map during the flood tide. The step between lines is $3 \mathrm{~mm}$. (C) Averaged sedimentation rates $\left(\mathrm{g} \mathrm{cm}^{-2}\right.$ year $\left.^{-1}\right)$ over several tidal cycles.

dealing with $\mathrm{Th}, \mathrm{U}$ or $\mathrm{Ra}$. These parameters have been obtained from literature data and direct field measurements. They are the mean radius and density of suspended matter particles, bulk density of the sediment, mean radius of the large grain size fraction of sediment particles, mixing depth and the dry weight fraction of small particles within the mixing depth. These parameters are presented in Periáñez et al. (1996a). The geometrical accessibility factors were obtained from a calibration exercise (Periáñez et al. 1996a).

As the rate of change of activity in the sediment is slow, there are no significant changes during periods of several days (typical simulated times). Consequently, we use experimental values of $U$ and $T h$ concentrations in sediments as initial conditions, instead of considering zero concentrations at $t=0$. These experimental values have been obtained from Martínez-Aguirre et al. (1994b).

Coefficients $\chi_{1}$ and $k_{2}$ were obtained, in the case of ${ }^{226} \mathrm{Ra}$, from laboratory experiments (Periáñez, 1995). These experiments were carried out with unfiltered water of the Odiel river, in such a way that laboratory conditions were as close as possible to the natural conditions in the estuary. In previous work (Nyffeler et al., 1984), kinetic transfer coefficients were 
measured for a wide set of elements. It was found that there was a very small variation in $k_{2}$ (less than an order of magnitude) for elements that have a very different behaviour, such as $\mathrm{Th}, \mathrm{Sh}, \mathrm{Hg}, \mathrm{Pa}, \mathrm{Zn}, \mathrm{Sb}, \mathrm{Cs}, \mathrm{Se}, \mathrm{Cd}$, $\mathrm{Ba}, \mathrm{Sr}$ and $\mathrm{Na}$. This small variation opens up the possibility (Nyffeler $e t$ al., 1984) of estimating $\chi_{1}$ for elements without laboratory experiments. Thus, the $\chi_{1}$ of $\mathrm{U}$ and Th can be calculated using the $k_{2}$ of ${ }^{226} \mathrm{Ra}$ and the $k_{\mathrm{d}}$ of $\mathrm{U}$ and $T h$, since a relationship between $k_{\mathrm{d}}, k_{2}$ and $\chi_{1}$ (Periáñez et al., 1996a) can be obtained. The value of $k_{2}$, from the laboratory experiments (Periáñez, 1995), is $k_{2}=8.17 \times 10^{-6} \mathrm{~s}^{-1}$. The mean value of the distribution coefficient of $U$ has been obtained from IAEA (1985), since it is in agreement with measurements in the Odiel river (Table 4). In the case of Th, however, the mean $k_{\mathrm{d}}$ has been calculated from Table 4 since results in the table are smaller than the mean value of the Th distribution coefficient $\left(20001 \mathrm{~g}^{-1}\right.$; IAEA, 1985). Then, for $\mathrm{U}, \chi_{1}=1.06 \times 10^{-7} \mathrm{~m} \mathrm{~s}^{-1}$ and for $\mathrm{Th}$, $\chi_{1}=1.46 \times 10^{-6} \mathrm{~m} \mathrm{~s}^{-1}$. The exchange velocity, $\chi_{1}$, of Th is an order of magnitude larger than that of $U$, revealing the larger affinity of Th to be fixed to the solid phases. These exchange velocities, although perhaps not exact values, seem to be good estimates since the model produces, as will be seen, results in good agreement with the experimental data.

The source terms of dissolved and particulate $U$ and $T h$ to the river were unknown (in both temporal sequence and magnitude). Thus, they were changed, by trial and error, until the model reproduced the experimental data. The source is located in compartment $(7,23)$ since high peaks of U, Th (see Tables 1 and 3) and ${ }^{226} \mathrm{Ra}$ (Periáñez \& García-León, 1993; Periáñez et al., 1994a) were measured at this point. The results for $\mathrm{U}$ are presented in Fig. 4, for both low- and high-water samples.

High and low-water samples were collected with a time difference of $18 \mathrm{~h}$ between them. Generally speaking, peaks should correspond with discharges performed shortly before or during sampling, while, when a flat distribution is measured, it should correspond with the background that remains in the river after the homogenization of discharges performed earlier than sampling. As the experimental data used to model the ${ }^{226} \mathrm{Ra}$ dispersion were obtained from this same set of samples in which $U$ and $T h$ have been measured, the time sequence of the input must be the same as that for ${ }^{226} \mathrm{Ra}$. A first activity input began in tidal cycle 1 and lasted for $3.3 \mathrm{~h}$. High water concentrations were obtained two cycles later (cycle 3 ). A second input started in cycle 4 and lasted for $9 \mathrm{~h}$. Low water concentrations were obtained from this cycle. In this way, $18 \mathrm{~h}$ elapsed between the timepoints in which concentrations for high and low water are obtained. Thus, the sampling campaign conditions are reproduced. A more detailed discussion about the reasons for selecting this time sequence for the input rates can be seen in Periáñez et al. (1994b). 

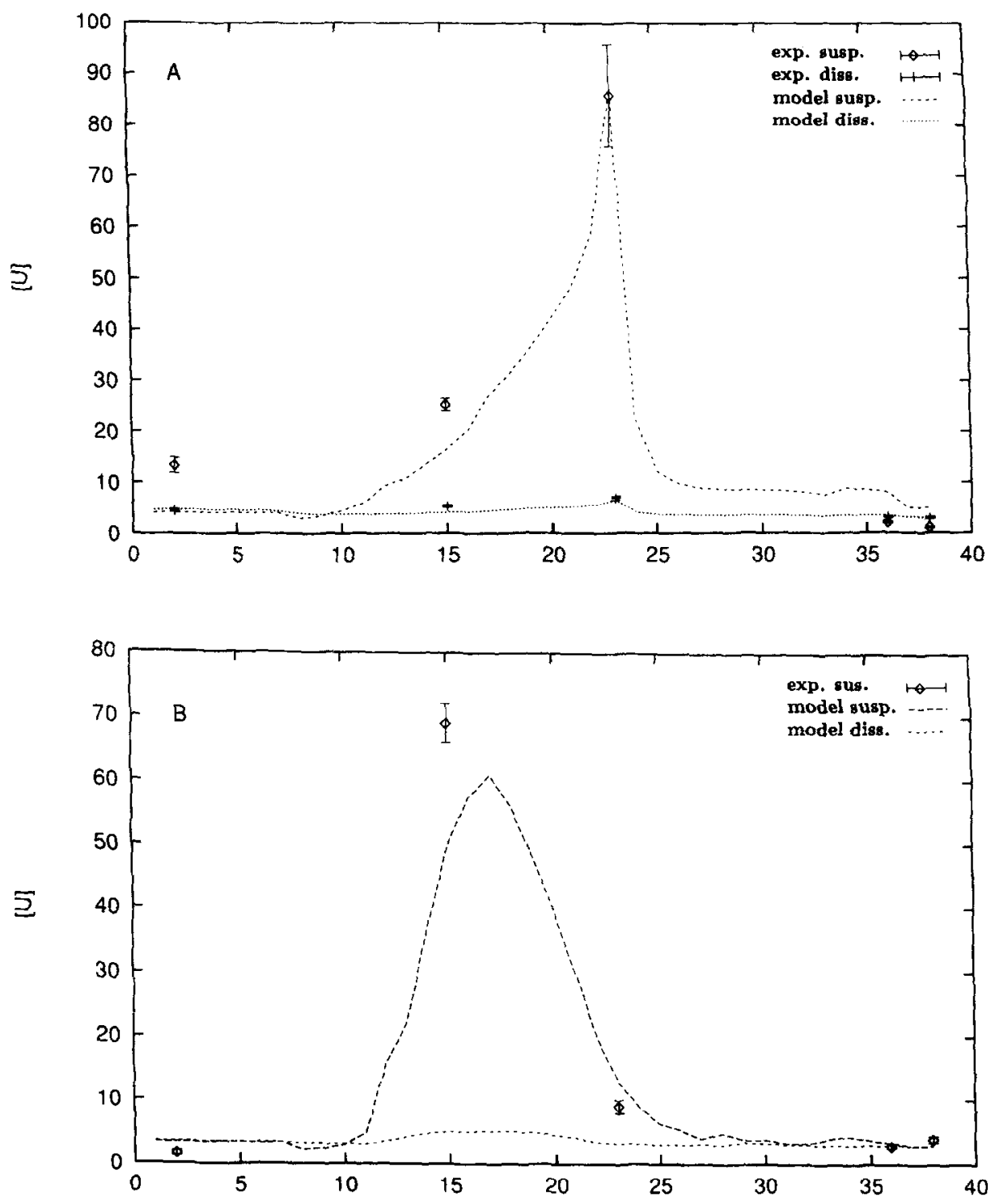

Fig. 4. Model results for $U$ dispersion, for the (A) low- and (B) high-water samples. Uranium concentrations in water are given in $\mu \mathrm{g} \mathrm{I}^{-1}$ and in suspended matter in $\mu \mathrm{g} \mathrm{g}^{-1}$. Points are the measured concentrations and lines are the model results. The $x$-axis is the position in the grid.

The first input rates were $1.4 \times 10^{6}$ and $1.1 \times 10^{2} \mathrm{mg}$ of $\mathrm{U}$ per time step for the dissolved phase and suspended matter, respectively. For the second input, the input rates were $1.3 \times 10^{6}$ and $1.0 \times 10^{2} \mathrm{mg}$ per time step for water and suspended matter, respectively. The ratio between the $U$ 
discharged in dissolved and particulate forms was obtained from a trial and error exercise. The first input is used to create the $U$ background that exists in the river, although there are no discharges from the fertilizer plants. Meteorological conditions (wind speed and direction and atmospheric pressure) for the sampling date (Periáñez et al., 1994b) were also introduced in the model.

It can be seen in Fig. 4 that there is a good agreement between the computed and measured U-concentrations in both phases and in both low and high water samples. Unfortunately, computed U-concentrations for the dissolved phase high water samples could not be compared with experimental data. Nevertheless, the model result must be a good estimate of the $U$ content in water during high water since the remainder of the experimental data are well reproduced and the ratio between the $U$ discharged in water and suspended matter is the same for the two inputs. Because the rate of change of concentrations in sediments is slow, there are no significant changes during some tidal cycles and they are not included in this discussion.

Measured and computed distribution coefficients for the low water samples can be seen in Fig. 5. The model reproduces the general behaviour of the $k_{\mathrm{d}}$ along the river, giving a good agreement with the experimental data. Thus, the $k_{\mathrm{d}}$ variability, between different points, commented on in Section 3, can be reproduced by the model. It seems that the description of the partition of radiotracers between solid and liquid phases in terms of the kinetic transfer coefficients and the exchange surface is adequate.

The time sequence of the discharges of $T h$ is, of course, the same as that for ${ }^{226} \mathrm{Ra}$ and $\mathrm{U}$. The first input rates (used to create the background) were $3.3 \times 10^{4}$ and $2.6 \times 10^{2} \mathrm{mg}$ per time step for dissolved and suspended $\mathrm{Th}$, respectively. For the second input, the input rates were $1.9 \times 10^{4}$ and $1.5 \times 10^{2} \mathrm{mg}$ per time step for water and suspended matter, respectively.

The experimental and model results are presented in Fig. 6(A-C). The low water results are presented in different figures because, otherwise, the different scales would not permit an appreciation of the details. It can be seen that the general behaviour of Th is well reproduced by the model. It is interesting to note that the model is able to reproduce spatial variations of Th concentrations of threc orders of magnitude (see Table 1), which shows the goodness of our description. As in the case of $U$, the model results for the dissolved phase high water samples could not be compared with the experimental data. However, for the same reasons as in the case of $U$, the model result must be a good estimate of the Th content in water during high water.

The computed $k_{\mathrm{d}}$ for Th can be seen in Fig. 7. The general behaviour is again reproduced by the model. The $\mathrm{Th} / \mathrm{U}$ mass ratios have also been investigated with our model. They are presented in Fig. 8(A-C). The 


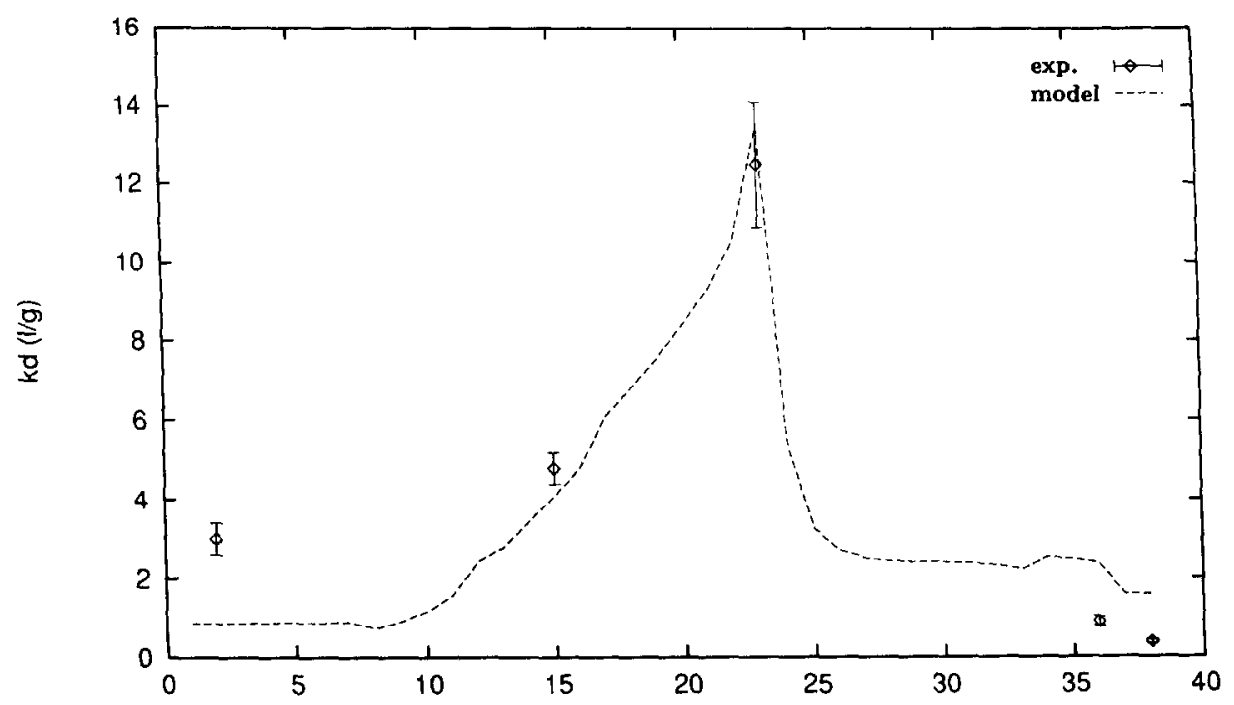

Fig. 5. Computed (line) and measured (points) distribution coefficient $\left(\mathrm{lg}^{-1}\right)$ for $U$ during low water.

general behaviour of the $\mathrm{Th} / \mathrm{U}$ mass ratios is well reproduced by the model in all cases. It was mentioned in Section 3 that the U excess with respect to $\mathrm{Th}$ in suspended matter indicates the existence of an external source of $U$ contaminated particles to the river. There was, however, an

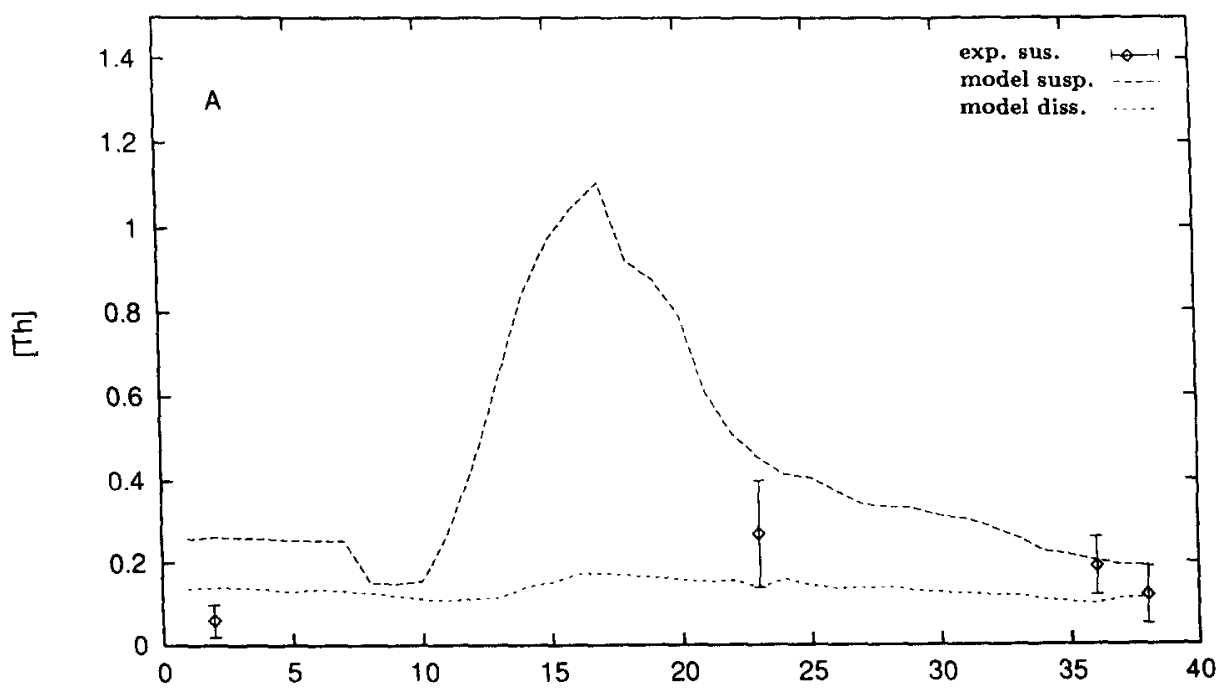

Fig. 6. Model results for Th dispersion. (A) Water and suspended matter during high water. (B) Suspended matter during low water. (C) Water during low water. Concentrations are given in $\mu \mathrm{g}^{-1}$ and $\mu \mathrm{g} \mathrm{g}^{-1}$ for water and suspended matter samples, respectively. 

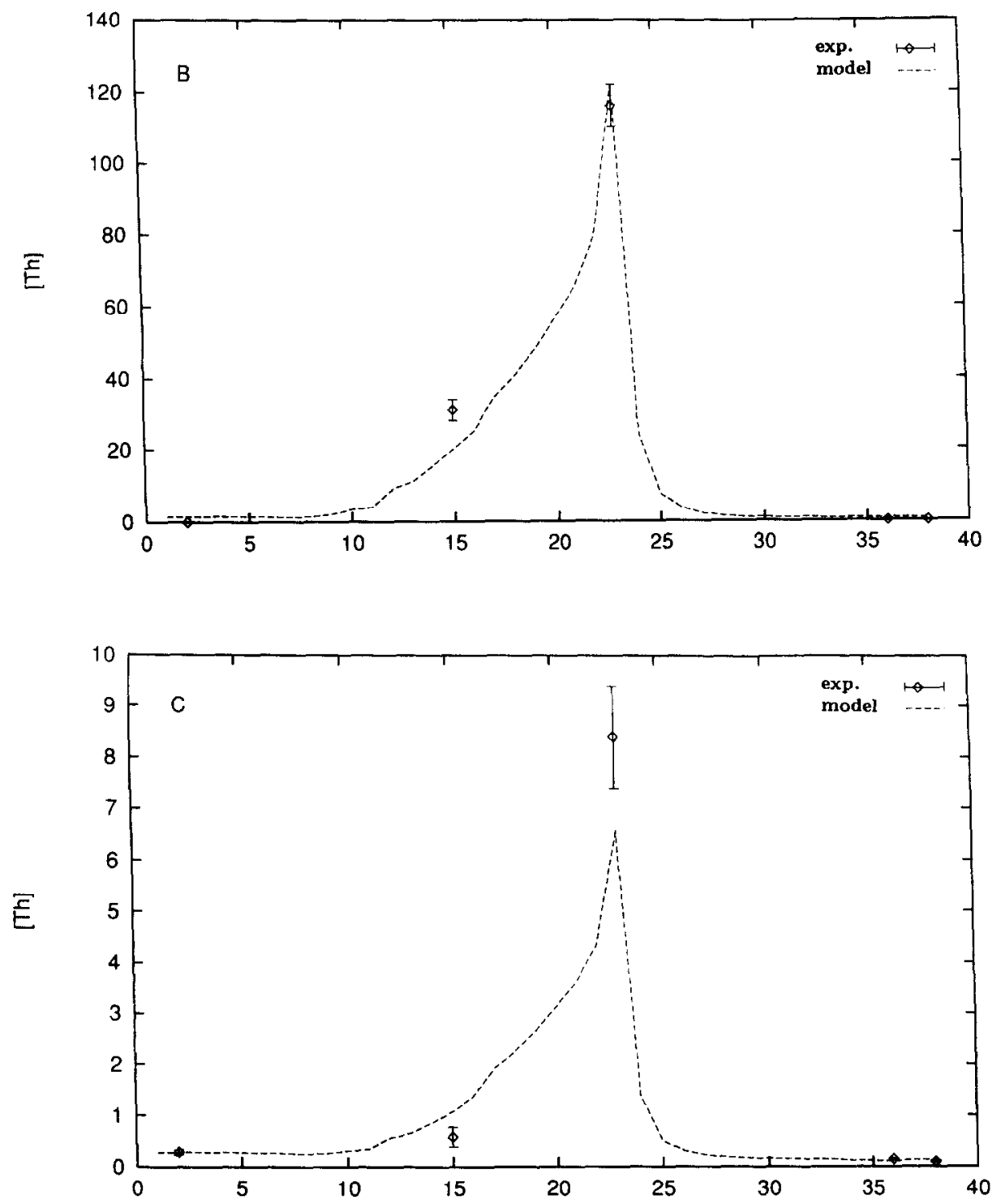

Fig. 6. Continued.

exception (samples SO4 and SO5 which were the most contaminated). Indeed, more $T h$ than $\mathrm{U}$ is discharged into the river, in both dissolved and suspended forms. From the second input rates (the first are not indicative because they are used just to create the background), it can be shown that, in solution, $T h / U=2.4$, and in suspended matter, $T h / U=1.5$. Thus, more Th than $U$ is discharged and, as a consequence, there is an excess of Th in water and suspended matter near the source. However, there is an 


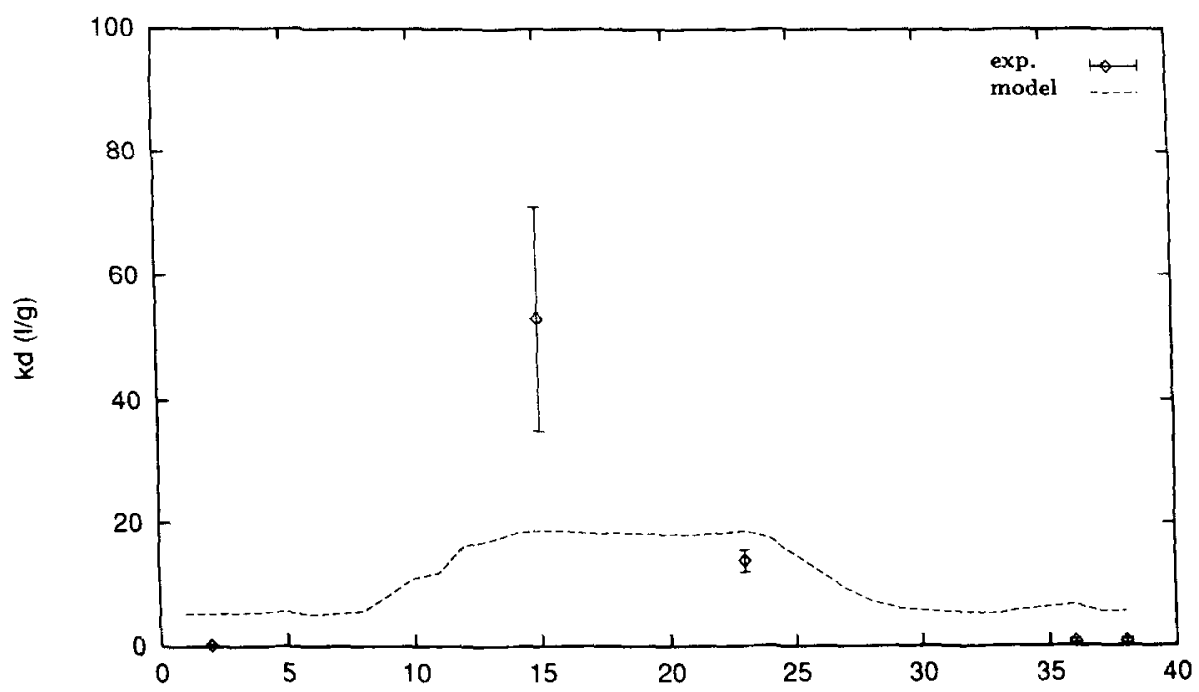

Fig. 7. Computed (line) and measured (points) distribution coefficient $\left(1 \mathrm{~g}^{-1}\right)$ for Th during low water.

excess of $U$ in the rest of the river in both liquid and suspended phases. It seems clear that the dissolved Th that is released to the river is quickly fixed to solid particles, and these particles (together with the particles that are released from the source and are rich in $\mathrm{Th}$ ) are deposited on the river

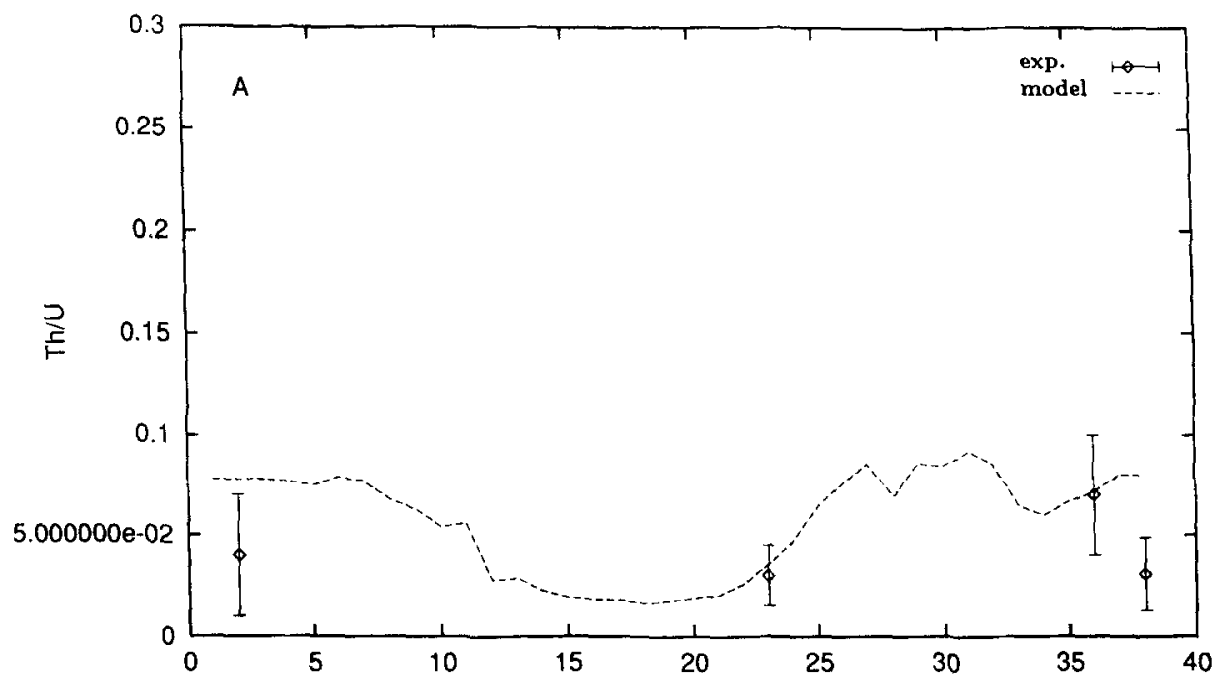

Fig. 8. Computed (lines) and measured (points) Th/U mass ratios for suspended matter samples during high water (A), water samples during low water (B), and suspended matter samples during low water (C). 

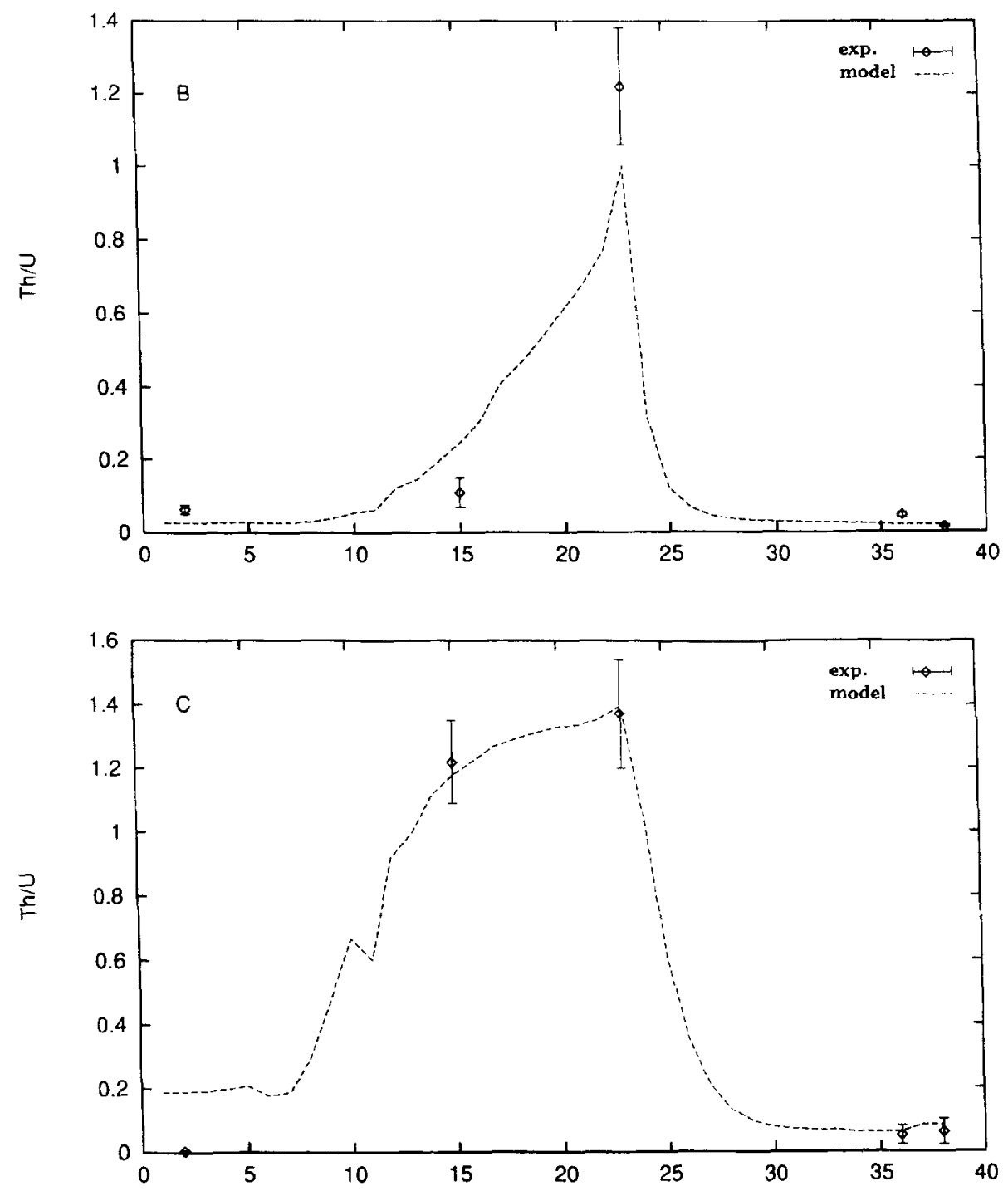

Fig. 8. Continued.

bed near the source. In this way, a $\mathrm{U}$ excess would exist in the rest of the river, as confirmed by the experimental and the model results. This hypothesis is also supported by the fact that an excess of Th has been measured in sediments collected close to the fertilizer complex (MartínezAguirre et al., 1994b).

The sensitivity of the model to the different parameters, the way of creating the background and the magnitude of the source term have already been studied (Periáñez et al., 1994b, 1996a,c). 


\section{CONCLUSIONS}

Uranium and Th concentrations have been measured in water and suspended matter samples in an estuarine system affected by waste disposal from a fertilizer processing complex. Distribution coefficients have also been calculated. The results have shown a radioactive impact and a significant $k_{\mathrm{d}}$ variability. In order to perform a quantitative study on the distribution of $U$ and $T h$, as well as on the $k_{\mathrm{d}}$ variability, a modelling study has been carried out.

The model includes the partition of radiotracers between four phases, and this partition is based on a kinetic approach. The model solves the hydrodynamic equations, the suspended matter equations and the four equations that govern the time evolution of the radiotracer concentrations in each one of the four phases.

The model results are in good agreement with the experimental data for both $\mathrm{U}$ and $\mathrm{Th}$, and for both water and suspended matter samples. The $k_{\mathrm{d}}$ variability is reproduced by the model, as well as the $\mathrm{Th} / \mathrm{U}$ mass ratios. This shows the goodness of the description of the transfer processes, since good results are obtained for elements with a very different chemical behaviour ( $\mathrm{Ra}, \mathrm{U}, \mathrm{Th}$ ) by simply changing the value of a parameter: the exchange velocity.

\section{ACKNOWLEDGEMENTS}

This work was partially supported by ENRESA. The author is indebted to J. M. Abril for help in the modelling work.

\section{REFERENCES}

Abril, J. M. \& García-León, M. (1993). A 2D-4 phases marine dispersion model for radionuclides. Part 1: conceptual and computational model. J. Environ. Radioact., 20, 71-88.

Bertine, K. K., Chan, L. H. \& Turekian, K. K. (1970). Uranium determinations in deep-sea sediments and natural waters using fission tracks. Geochim. Cosmochim. Acta, 34, 641-8.

Bhat, S. G. \& Krishnaswamy, S. (1969). Isotopes of uranium and radium in Indian rivers. Proc. Indian Acad. Sci., 70, 1-17.

Flather, R. A. (1994). A storm surge prediction model for the northern bay of Bengal with application to the cyclone disaster in April 1991. J. Phys. Oceanogr., 24, 172-90.

Flather, R. A. \& Heaps, N. S. (1975). Tidal computations for Morecombe bay. Geophys. J. R. Astr. Soc., 42, 489-517. 
Gurbutt, P. A., Kershaw, P. J. \& Durance, J. A. (1987). Modelling the distribution of soluble and particle adsorbed radionuclides in the Irish sea. In Radionuclides. A Tool for Oceanography, eds J. C. Guary, P. Guegueniat \& R. J. Pentrcath. Elsevier Science, Amsterdam, pp. 395-490.

Howorth, J. M. \& Eggleton, A. E. J. (1988). Modelling the sea to land transfer of marine discharges from Sellafield: validation against environmental measurements. In Reliability of Radioactive Transfer Models, ed. G. Desmet. Elsevier Applied Science, Barking, pp. 261-7.

IAEA (1985). Sediment $k_{\mathrm{d}}$ and concentration factors for radionuclides in the marine environment. Technical Reports Series 247.

Laiche, T. P. \& Scott, L. M. (1991). A radiological evaluation of phosphogypsum. Hlth Phys., 60, 691-3.

Li, Y. H., Burkhardt, L., Buchholtz, M., O'Hara, P. \& Santschi, P. H. (1984). Partition of radiotracers between suspended particles and seawater. Geochim. Cosmochim. Acta, 48, 2011-9.

Mangini, A., Sonntag, L., Bertsch, G. \& Muller, E. (1979). Evidence for a high natural uranium content in world rivers. Nature, 278, 337-9.

Martínez-Aguirre, A. (1991). Radioactividad natural en diversos compartimentos naturales de Andalucía. PhD Thesis. Universidad de Sevilla (in Spanish).

Martínez-Aguirre, A., García-León, M. \& Ivanovich, M. (1994a). U and Th distribution in solution and suspended matter from rivers affected by phosphate rock processing in southwestern Spain. Nucl. Instr. Meth., A339, 28793.

Martínez-Aguirre, A., García-León, M. \& Ivanovich, M. (1994b). The distribution of $\mathrm{U}$, Th and ${ }^{226} \mathrm{Ra}$ derived from the phosphate fertilizer industries on an estuaring system in southwest Spain. J. Envron. Radioact., 22, 155-77.

Miyake, Y., Sugimura, Y. \& Yasujima, T. (1973). Th isotope content in river water in Japan. Papers Meteorol. Geophys., 24, 67-73.

Moore, W. S. (1967). Amazon and Mississippi river concentration of uranium, thorium and radium isotopes. Earth Planet. Sci. Letts, 2, 231-4.

Nyffeler, U. P., Li, Y. H. \& Santschi, P. H. (1984). A kinetic approach to describe trace-element distribution between particles and solution in natural aquatic systems. Geochim. Cosmochim. Acta, 48, 1513-22.

Periáñez, R. (1995). Un modelo matemático para la simulación de la dispersión de radionúclidos no conservativos en un sistema estuario. Aplicación a la ría de Huelva. PhD Thesis. Universidad de Sevilla (in Spanish).

Periáñez, R. \& García-León, M. (1993). Ra-isotopes around a phosphate fertilizer complex in an estuarine system at the southwest of Spain. J. Radioanalyt. Nucl. Chem. Articles, 172, 71-9.

Periáñez, R., García-León, M. \& Abril, J. M. (1994a). Radium isotopes in suspended matter in an estuarine system at the southwest of Spain. J. Radioanalyt. Nucl. Chem. Articles, 183, 395-407.

Periáñez, R., Abril, J. M. \& García-León, M. (1994b). A modelling study of the ${ }^{226} \mathrm{Ra}$ dispersion in an estuarine system in southwest Spain. J. Environ. Radioact., 24, 159-79.

Periáñez, R., Abril, J. M. \& García-León, M. (1996c). Modelling the suspended matter distribution in an estuarine system. Application to the Odiel river in southwest Spain. Ecol. Model., 87, 169-79.

Periáñez, R., Abril, J. M. \& García-León, M. (1996a). Modelling the dispersion 
of non-conservative radionuclides in tidal waters. Part 2: application to ${ }^{226} \mathbf{R a}$ dispersion in an estuarine system. $J$. Environ. Radioact., 31, 253-72.

Periáñez, R., Abril, J. M. \& Garcia-León, M. (1996b). Modelling the dispersion of non-conservative radionuclides in tidal waters. Part 1: conceptual and mathematical model. J. Environ. Radioact., 31, 127-41.

Prandle, D. (1974). A numerical model of the southern North sea and the river Thames. IOS $/ \mathrm{R} / 4$.

Prandle, D. (1984). A modelling study of the mixing of ${ }^{137} \mathrm{Cs}$ in the seas of the European continental shelf. Phil. Trans. R. Soc. Lond., A310, 407-36.

Pugh, D. T. (1987). Tides, Surges and Mean Sea Level. John Wiley, Chichester.

Scott, M. R. (1982). The chemistry of U- and Th-series nuclides in rivers. In

Uranium Series Disequilibrium: Applications to Environmental Problems, eds

M. Ivanovich \& R. S. Harmon. Clarendon Press, Oxford, pp. 181-201.

Van der Heijde, H. B., Klijn, P. J. \& Passchier, W. F. (1988). Radiological impacts of the disposal of phosphogypsum. Radiat. Prot. Dosim., 24, 41923.

\section{APPENDIX}

\section{Dissolved phase}

$$
\frac{\partial C_{\mathrm{d}}}{\partial t}=-k_{1} C_{\mathrm{d}} \frac{H}{H^{*}}+k_{2} C_{\mathrm{s}} m \frac{H}{H^{*}}+k_{2}\left(\operatorname{sed}_{\mathrm{s}}+\operatorname{sed}_{1}\right)+(\mathrm{adv}+\mathrm{dif}),
$$

where $C_{\mathrm{d}}$ and $C_{\mathrm{s}}$ are the radionuclide concentrations in water $\left(\mathrm{mg} \mathrm{m}^{-3}\right)$ and suspended matter $\left(\mathrm{mg} \mathrm{g}^{-1}\right)$, respectively, $m$ is the suspended matter concentration $\left(\mathrm{mgl}^{-1}\right)$ and $H$ is the water column height. The time derivative must be interpreted as in a forward finite differences scheme. The * means that the corresponding quantity must be cvaluated in the new time step. The first term represents the transfer of radionuclides from water to the three solid phases. Thus, $k_{1}$ is given by eqn (3). adv + dif represents advective plus diffusive transport of dissolved radionuclides from one grid cell to another. The third term is the transfer of radionuclides from the two fractions of sediments to water:

$$
\begin{aligned}
& \operatorname{sed}_{\mathrm{s}}=\frac{a_{\mathrm{s}} L \rho_{\mathrm{m}} f \psi}{H^{*}} 10^{3} \\
& \operatorname{sed}_{1}=\frac{a_{1} L \rho_{\mathrm{m}}(1-f) \psi^{\prime}}{H^{*}} 10^{3},
\end{aligned}
$$

where $a_{\mathrm{s}}$ and $a_{1}$ are the radionuclide concentrations in the small and the large grain size fraction of the sediments, respectively $\left(\mathrm{mg} \mathrm{g}^{-1}\right)$. The bulk density of the sediment, $\rho_{\mathrm{m}}$, is given in $\mathrm{kg} \mathrm{m}^{-3}$. 


\section{Suspended matter}

$$
\frac{\partial C_{\mathrm{s}}}{\partial t}=k_{1} \frac{C_{\mathrm{d}} H}{m^{*} H^{*}}-k_{2} C_{\mathrm{s}} \frac{m H}{m^{*} H^{*}}+(\text { res }-\mathrm{dep})+(\mathrm{adv}+\mathrm{dif}) .
$$

As the first term is the transfer of radionuclides from water to just suspended matter, $k_{1}$ is given by the first term of eqn (3). adv + dif is the advective plus diffusive transport of radionuclides in suspended matter. The sccond term is the transfer of radionuclides from suspended matter to water, and res and dep represent the resuspension and deposition processes:

$$
\begin{aligned}
& \text { dep }=\frac{v_{\mathrm{d}} C_{\mathrm{s}} m}{m^{*} H^{*}}\left(1-\frac{q}{v_{\mathrm{cd}}}\right) \\
& \text { res }=\frac{v_{\mathrm{r}} f \rho_{\mathrm{m}} a_{\mathrm{s}}}{m^{*} H^{*}}\left(\frac{q}{v_{\mathrm{cr}}}-1\right) 10^{3},
\end{aligned}
$$

where $v_{\mathrm{d}}$ and $v_{\mathrm{r}}$ are the mean deposition and resuspension velocities, $v_{\mathrm{cd}}$ and $v_{\mathrm{cr}}$ are the critical deposition and resuspension velocities and $q$ is the water flux velocity.

Both in the dissolved phase and in the suspended matter equations, the external sources of radionuclides must be included in the grid cells in which they exist.

\section{Sediments}

The equation for the small grain size fraction is:

$$
\frac{\partial a_{\mathrm{s}}}{\partial t}=k_{1} \frac{C_{\mathrm{d}} H}{\rho_{\mathrm{m}} L f} 10^{3}-k_{2} a_{\mathrm{s}} \psi+(\mathrm{dep}-\text { res }) .
$$

The first term is the transfer from water to the small fraction of the sediment. Thus, $k_{1}$ is given by the second term of eqn (3). The second term is the transfer of radionuclides from the sediment to water and dep - res represents the transfers between the sediment and suspended matter (through deposition and resuspension):

$$
\begin{aligned}
& \text { dep }=\frac{v_{\mathrm{d}} C_{\mathrm{s}} m}{L \rho_{\mathrm{m}} f}\left(1-\frac{q}{v_{\mathrm{cd}}}\right) 10^{-3} \\
& \text { res }=\frac{v_{\mathrm{r}} a_{\mathrm{s}}}{L}\left(\frac{q}{v_{\mathrm{cr}}}-1\right) .
\end{aligned}
$$


The equation for the large grain size fraction of the sediment is:

$$
\frac{\partial a_{1}}{\partial t}=k_{1} \frac{C_{\mathrm{d}} H}{L \rho_{\mathrm{m}}(1-f)} 10^{-3}-k_{2} a_{1} \psi^{\prime}
$$

where the first term is the transfer of radionuclides from water to the sediment $\left[k_{1}\right.$ is given by the third term of eqn (3)], and the second term represents the inverse process. 